\title{
CARBON MONOXIDE AND RESPIRATORY SYMPTOMS IN YOUNG ADULT PASSIVE SMOKERS: A PILOT STUDY COMPARING WATERPIPE TO CIGARETTE
}

\author{
ROUBA KAREN ZEIDAN ${ }^{1}$, SAMAR RACHIDI ${ }^{1}$, SANAA AWADA ${ }^{1}$, AMAL EL HAJJE ${ }^{1}$, WAFAA EL BAWAB, \\ JOSEPH SALAMÉ ${ }^{2}$, RACHELLE BEJJANY ${ }^{3}$, and PASCALE SALAMEH ${ }^{1}$
}

${ }^{1}$ Lebanese University, Hadath, Lebanon

Faculty of Pharmacy, Laboratory of Clinical and Epidemiological Research

${ }^{2}$ Charité Medical University Hospital, Berlin, Germany

${ }^{3}$ Lebanese University, Hadath, Lebanon

Doctoral School of Sciences \& Technology

\begin{abstract}
Objectives: Studies have correlated second hand smoke (SHS) with many diseases, especially respiratory effects. The goal of this study was to measure the impact of SHS on the respiratory symptoms and exhaled carbon monoxide. Material and Methods: The study population consisted of 50 young workers in restaurants serving waterpipes, 48 university students who sit frequently in the university cafeteria where cigarette smoking is allowed and 49 university students spending time in places where smoking is not allowed. Subjects completed questionnaires on socio-demographic characteristics, respiratory symptoms and exposure to SHS. Exhaled carbon monoxide levels were measured. ANOVA and Chi-square tests were used when applicable as well as linear and logistic regression analysis. Results: Exposure to cigarette smoke in university (adjusted odds ratio $(\mathrm{ORa})=6.06)$ and occupational exposure to waterpipe smoke $(\mathrm{ORa}=7.08)$ were predictors of chronic cough. Being married $(\mathrm{ORa}=6.40)$, living near a heavy traffic road $(\mathrm{ORa}=9.49)$ or near a local power generator $(\mathrm{ORa}=7.54)$ appeared responsible for chronic sputum production. Moreover, predictors of chronic allergies were: being male $(\mathrm{ORa}=7.81)$, living near a local power generator $(\mathrm{ORa}=5.52)$ and having a family history of chronic respiratory diseases $(\mathrm{ORa}=17.01)$. Carbon monoxide levels were augmented by the number of weekly hours of occupational exposure to waterpipe smoke $(\beta=1.46)$ and the number of daily hours of exposure to cigarette smoke $(\beta=1.14)$. Conclusions: In summary, young non-smoker subjects demonstrated more chronic cough and elevated carbon monoxide levels when exposed to SHS while the effect of waterpipe was even more evident.
\end{abstract}

\section{Keywords:}

Second hand smoke, Carbon monoxide level, Respiratory health, Waterpipe smoke, Cigarette smoke

This work was supported by the Lebanese University fund to the Clinical \& Epidemiological Research Laboratory (Unit 0037). Manager of project: Pascale Salameh, PharmD, MPH, PhD.

Received: December 5, 2013. Accepted: January 15, 2014.

Corresponding author: P. Salameh, Faculty of Pharmacy, Lebanese University, Hadath campus, Beirut, Lebanon (e-mail: pascalesalameh1@hotmail.com). 


\section{INTRODUCTION}

The World Health Organization estimates that 700 million people are exposed to Second Hand Smoke (SHS) worldwide [1]. SHS is formed by the side stream smoke emitted from the smoldering of cigarettes and other tobacco products between puffs and from the mainstream smoke exhaled by smokers [1]. SHS is now well-known to be a major menace to public health due to its acknowledged harmful health effects [2-7]. Passive smoking also increases severity and risk of asthma and respiratory symptoms [8-10], as well as a significant impairment of lung function $[11,12]$.

Nowadays, in Lebanon, as in many other countries, waterpipe smoking constitutes a trend; waterpipe active smoking seems to cause several respiratory symptoms and chronic diseases, such as chronic bronchitis, chronic obstructive pulmonary disease, and others [13-15]. However, few studies were carried out to evaluate the effect of its associated SHS: the observed indoor air pollution by various harmful elements during a waterpipe session is substantial, and the exposure is likely to constitute a serious health hazard [16]. Studies performed in the laboratory [17] and among real life smokers [18] showed that chemical toxicants contained in waterpipe mainstream are numerous, while particularly carbon monoxide seems to be a good marker of exposure when measured in exhaled air [19]. It remains to be established whether the same is true about the side stream exposure (passive smoking) and its adverse health effects.

The aim of the present study was to measure the effect of SHS on respiratory symptoms and exhaled carbon monoxide (ECO) levels by comparing the selected respiratory indices in subjects exposed to cigarette and waterpipe second-hand smoke and those recorded in non-smokers.

\section{MATERIAL AND METHODS}

\section{Type of the study}

This is a cross-sectional descriptive pilot study comparing the effects of waterpipe and cigarette passive smoking exposure, performed over 3 groups of individuals: nonsmokers exposed to second-hand (SH) waterpipe smoke, non-smokers exposed to SH cigarette smoke, and nonsmokers who were not exposed to any type of smoke.

\section{Study population}

A total of 147 non active smokers from Beirut were included in the study; they were selected by empirical sampling. Fifty of them are workers in restaurants that serve waterpipes, 48 are university students who stay frequently in the university restaurant where cigarette smoking is allowed, and 49 are university students who frequently attend the university restaurant where smoking is not allowed.

The participants were between 18 and 35 years, non-asthmatic, and non active smokers (neither current nor previous smoking was allowed). Asthma was defined as a positive answer to the question: "has the doctor ever told you that you had asthma?", while active smoking was defined as a positive answer to the question: "have you ever smoked cigarette or waterpipe (more than one trial)?". A positive answer to any of these 2 questions was an exclusion criterion.

The study was carried out in the workplace (for the group or restaurant workers) and the cafeterias (for university students). After explaining the objectives of the study, a face-to-face interview was carried out using a standardized questionnaire to eligible individuals. The questionnaire was divided into several parts: socio-demographic characteristics (age, sex, marital status, and education), respiratory health questions (regarding chronic respiratory diseases / chronic bronchitis defined as "morning productive cough for more than 3 months a year for more than 2 years?" [20], as well as respiratory symptoms outside flu periods, such as chronic cough, chronic sputum production, chronic wheezing and upper respiratory tract allergy types), assessment of present passive smoking exposure duration (for both cigarette and waterpipe smoking, we asked about current estimated duration of exposure in hours per day and per week, respectively), and evaluation 
of other known potential source of carbon monoxide such as living near local power plants and biomass fuel use for cooking and house heating [21].

\section{Carbon monoxide measurement}

Measurements of the expired-air carbon monoxide (CO) levels were also performed in all individuals to improve exposure evaluation precision, using a calibrated CO-tester (CO - Tester-NG, F.I.M); ECO was reported in terms of parts per million (ppm), after taking into account the local environmental carbon monoxide concentration during calibration.

\section{Statistical analysis}

Data entry and analysis were performed using SPSS statistical software, version 20.0. The level of significance was set at 0.05 (rejection of the null hypothesis at $\mathrm{p}<0.05$ ). Differences in the baseline characteristics between the exposure groups were evaluated using Pearson Chi-square test to compare percentages of nominal variables between groups, and ANOVA to compare means of the continuous variables: in fact, ANOVA could be used because the sample size was $>30$ in every subgroup of comparison, and because sample sizes were almost equal [22]. For identification of groups differing significantly, post hoc test with Bonferroni correction was used. These tests were then used to study the differences of current and previous sources of exposure to carbon monoxide as well as personal and family disease history and respiratory symptoms between the groups.

To study the predictors of carbon monoxide levels, a multiple linear regression was carried out, with carbon monoxide, in ppm, as the dependent variable. Independent variables were all variables that could influence the $\mathrm{CO}$ in exhaled air in addition to socio-demographic variables: number of weekly hours of occupational exposure to waterpipe smoke, biomass fuel use for home heating, house close to a heavy traffic road, house close to a local power generator, home exposure to tobacco smoke, number of daily hours of exposure to cigarette smoke in the university, in addition to education, sex, age, marital status, and body mass index.

We ensured the linearity of the relationship (using residual plots as function of predicted values), the normality of distribution of residuals (using the residuals histogram along with density of normal distribution and KolmogorovSmirnov test), and the non-colinearity of variables that were kept so that the model could be accepted (Variance Inflation Factors were used to check colinearity of variables). We then carried out stepwise logistic regression using likelihood ratio test to determine the best predictors of respiratory symptoms. The following definitions of the dependant variables for respiratory symptoms were used: chronic cough, chronic sputum production and chronic allergy. Because of the relatively low sample size, we used a forward stepwise selection procedure. After ensuring the adequacy of the models using the Hosmer-Lemeshow test, adjusted odds ratios (ORa) were calculated with $95 \%$ confidence intervals (CIs). Independent variables initially introduced in the models were the followings: exposure to cigarette smoke at university, occupational exposure to waterpipe smoke, age, sex, marital status, education, house close to a heavy traffic road, house close to a local power generator, biomass fuel use for house heating, family history of chronic respiratory disease, home exposure to tobacco smoke, chronic respiratory disease during childhood, parental smoking during childhood and fetal life, and body mass index. They were only introduced when absence of collinearity was ensured using the Variance Inflation Factors.

\section{RESULTS}

\section{Socio-demographic characteristics distribution}

In Table 1, exposure distribution is reported according to socio-demographic characteristics. There were significant differences between all subgroups: The non-exposed 
subjects and the ones exposed to cigarette smoke were mainly women (83.7\% and $58.3 \%$ respectively), whereas only men were exposed to waterpipe smoke. Moreover, the subjects exposed to waterpipe smoke were significantly older than the others: their mean age was $30.02 \pm 2.92$, and $74 \%$ of them were between the age 29 and 34. Non-exposed subjects as well as the ones exposed to cigarette smoke were mainly between the age of 18 and 22 (89.8\% and $97.9 \%$ respectively), none was older than 29, and they were all single university students, whereas the ones exposed to waterpipe smoke were evenly distributed between married and single, and mainly had a secondary education level or less $(82 \%)$.

\section{Exposure to carbon monoxide}

The examination of the current and previous sources of exposure to $\mathrm{CO}$ (Table 2) showed that restaurant workers exposed to waterpipe smoke were the least exposed to tobacco smoke at home (38\%), having the lowest number of smokers at home $(0.66 \pm 0.96)$ and the lowest daily hours of exposure to smoke at home $(0.94 \pm 1.58)$. They also had the lowest exposure rate to maternal smoke during childhood $(26 \%)$ leaving the ones exposed to cigarette smoke with the highest rate of $52.1 \%$. Moreover, the subjects non-exposed to smoke appeared to have the highest exposure rate to a local power generator (42.9\%). None of the participants used solid fuels for cooking.

On the other hand, the restaurant workers exposed to waterpipe smoke had the highest weekly hours of exposure to smoke at work (61.08 \pm 9.31$)$, characterized as exposure to waterpipe in cafés. There was a significant difference between the groups in ECO: with the workers exposed to waterpipe smoke having the highest level $(26.84 \pm 8.17$ parts per million), followed by the students exposed to cigarette smoke (12.25 \pm 2.96 parts per million) and finally the nonexposed students ( $3.76 \pm 1.70$ parts per million).

\section{Respiratory diseases and symptoms}

When examining respiratory diseases and symptoms (Table 3), the workers exposed to waterpipe smoke and students

Table 1. Comparison of socio-demographic characteristics

\begin{tabular}{|c|c|c|c|c|}
\hline Characteristic & $\begin{array}{l}\text { Non-exposed } \\
\quad(\mathrm{N}=49)\end{array}$ & $\begin{array}{l}\text { Exposed to waterpipe smoke } \\
\qquad(\mathrm{N}=50)\end{array}$ & $\begin{array}{l}\text { Exposed to cigarette smoke } \\
\qquad(\mathrm{N}=48)\end{array}$ & $\mathrm{p}$ \\
\hline $\operatorname{Sex}[\mathrm{n}(\%)]$ & & & & $<0.001$ \\
\hline male & $8(16.3)$ & $50(100)$ & $20(41.7)$ & \\
\hline female & $41(83.7)$ & 0 & $28(58.3)$ & \\
\hline Age (years), $\mathrm{M} \pm \mathrm{SD}$ & $20.14 \pm 1.41$ & $30.02 \pm 2.92^{*}$ & $19.69 \pm 1.22$ & $<0.001$ \\
\hline $18-22[\mathrm{n}(\%)]$ & $44(89.8)$ & $1(2.0)$ & 47 (97.9) & \\
\hline $23-28[\mathrm{n}(\%)]$ & $5(10.2)$ & $12(24.0)$ & $1(2.1)$ & \\
\hline $29-34[\mathrm{n}(\%)]$ & 0 & $37(74.0)$ & 0 & \\
\hline Marital status [n (\%)] & & & & $<0.001$ \\
\hline married & 0 & $25(50)$ & 0 & \\
\hline non-married & $49(100)$ & $25(50)$ & $48(100)$ & \\
\hline Education [n (\%)] & & & & $<0.001$ \\
\hline secondary or less & 0 & $41(82.0)$ & 0 & \\
\hline university student & $49(100)$ & $9(18.0)$ & $48(100)$ & \\
\hline
\end{tabular}

* Difference significant between exposed to waterpipe and non exposed to smoke, and between exposed to waterpipe and cigarette; difference nonsignificant between non-exposed and exposed to cigarette smoke. 
Table 2. Current and previous sources of exposure to carbon monoxide

\begin{tabular}{|c|c|c|c|c|}
\hline Characteristic & $\begin{array}{l}\text { Non-exposed } \\
(\mathrm{N}=49)\end{array}$ & $\begin{array}{c}\text { Exposed to waterpipe } \\
\text { smoke } \\
(\mathrm{N}=48)\end{array}$ & $\begin{array}{c}\text { Exposed to cigarette } \\
\text { smoke } \\
(\mathrm{N}=50)\end{array}$ & $\mathrm{p}$ \\
\hline Exposed to tobacco smoke at home $[\mathrm{n}(\%)]$ & $31(63.3)$ & $19(38.0)$ & $29(60.4)$ & 0.022 \\
\hline Smokers at home (n), $\mathrm{M} \pm \mathrm{SD}$ & $1.27 \pm 1.10$ & $0.66 \pm 0.96^{*}$ & $1.29 \pm 1.20$ & 0.006 \\
\hline \multicolumn{5}{|l|}{ Exposure to smoke, $\mathrm{M} \pm \mathrm{SD}$} \\
\hline at home (h/day) & $2.72 \pm 3.52$ & $0.94 \pm 1.58^{*}$ & $2.07 \pm 3.13$ & 0.009 \\
\hline at work/university (h/week) & 0 & $61.08 \pm 9.31^{*}$ & $3.42 \pm 2.47$ & $<0.001$ \\
\hline to waterpipe smoke in restaurants/cafés (h/week) & $3.71 \pm 4.65$ & $61.08 \pm 9.31^{*}$ & $3.04 \pm 9.10$ & $<0.001$ \\
\hline \multicolumn{5}{|l|}{ Home close $(<100 \mathrm{~m})[\mathrm{n}(\%)]$} \\
\hline to a heavy traffic road & $17(34.0)$ & $19(38.0)$ & $20(41.7)$ & 0.779 \\
\hline to a heavy traffic road (ever in the past) & $23(46.9)$ & $18(36.0)$ & $25(52.1)$ & 0.261 \\
\hline to a local power generator (ever in the past) & $21(42.9)$ & $9(18.0)$ & $9(18.0)$ & 0.007 \\
\hline Biomass use for heating & $28(57.1)$ & $38(76.0)$ & $28(58.3)$ & 0.091 \\
\hline \multicolumn{5}{|l|}{ Parents smoking during individual's fetal life [n (\%)] } \\
\hline mother & $9(18.4)$ & $12(24.0)$ & $5(10.4)$ & 0.093 \\
\hline father & $19(38.8)$ & $15(30.0)$ & $19(39.6)$ & 0.410 \\
\hline \multicolumn{5}{|l|}{ Parents smoking during individual's childhood [n (\%)] } \\
\hline mother & $17(34.7)$ & $13(26.0)$ & $25(52.1)$ & 0.001 \\
\hline father & $22(44.9)$ & $17(34.0)$ & $23(47.9)$ & 0.187 \\
\hline Carbon monoxide level in parts per million, $\mathrm{M} \pm \mathrm{SD}$ & $3.76 \pm 1.70$ & $26.84 \pm 8.17^{* *}$ & $12.25 \pm 2.96^{* *}$ & $<0.001$ \\
\hline
\end{tabular}

* Difference significant between exposed to waterpipe and others (exposed to cigarette smoke and non-exposed); no significant difference between non-exposed and exposed to cigarette smoke.

** Significant differences between non-exposed, exposed to cigarette smoke and waterpipe smoke taken two by two.

Table 3. Personal and family disease history and respiratory symptoms

\begin{tabular}{lcccc}
\hline \multicolumn{1}{c}{ Characteristic } & $\begin{array}{c}\text { Non-exposed } \\
(\mathrm{N}=49)\end{array}$ & $\begin{array}{c}\text { Exposed to waterpipe } \\
\text { smoke } \\
(\mathrm{N}=48)\end{array}$ & $\begin{array}{c}\text { Exposed to cigarette } \\
\text { smoke } \\
(\mathrm{N}=50)\end{array}$ & $\mathrm{p}$ \\
\hline Has a family history of a chronic respiratory disease & $4(8.2)$ & 0 & $1(2.1)$ & 0.067 \\
Has chronic cough & $8(16.3)$ & $29(58.0)$ & $26(54.2)$ & $<0.001$ \\
Has chronic sputum production & $3(6.1)$ & $3(6.0)$ & $1(2.1)$ & 0.569 \\
Has chronic bronchitis & $2(4.1)$ & $2(4.0)$ & 0 & 0.369 \\
Has chronic wheezing & $1(2.0)$ & 0 & $1(2.1)$ & 0.593 \\
Has chronic allergy & $9(18.4)$ & $1(2.0)$ & $2(4.2)$ & 0.006 \\
Has a childhood history of chronic respiratory disease & $1(2.0)$ & $1(2.0)$ & $1(2.1)$ & 0.732 \\
\hline
\end{tabular}


exposed to cigarette smoke manifested more chronic cough (58\% and $54.2 \%$ respectively) than the non-exposed students $(16.3 \%)$ who had, on the other hand, a higher rate of chronic allergy (18.4\%). We then looked at the effects of the number of years spent working in the same place on the respiratory symptoms of the workers in waterpipe serving restaurants. There was a significant difference in years spent working between those who suffered from chronic cough and those who did not $(3.9( \pm 4.741)$ and $2.19( \pm 4.046)$ years respectively, $p=0.02$ ), and again a significant difference regarding those who suffered from morning cough and those who did not $(4.86( \pm 4.962)$ and $2.45( \pm 4.169)$ years respectively, $\mathrm{p}=0.008)$.

\section{Multivariate analyses}

The multivariate analyses that were carried out for all individuals in this study are reported in Table 4. Men $(\beta=2.81)$ and individuals having a lower education

Table 4. Multivariate analysis of carbon monoxide and respiratory symptoms

\begin{tabular}{|c|c|c|c|}
\hline Dependent variable & Independent variable & $\begin{array}{c}\beta \\
(95 \% \mathrm{CI})\end{array}$ & $\mathrm{p}$ \\
\hline \multicolumn{4}{|l|}{ For multiple regression } \\
\hline \multirow[t]{4}{*}{$\begin{array}{l}\text { carbon monoxide in parts per } \\
\text { million* }\end{array}$} & $\begin{array}{l}\text { number of weekly hours of occupational exposure to } \\
\text { waterpipe smoke }\end{array}$ & $1.46(1.05-1.88)$ & $<0.001$ \\
\hline & $\begin{array}{l}\text { number of daily hours of exposure to cigarette } \\
\text { smoke in the university }\end{array}$ & $1.14(0.69-1.58)$ & $<0.001$ \\
\hline & lower education & $6.03(2.25-9.82)$ & 0.002 \\
\hline & male gender versus female & $2.81(0.45-5.16)$ & 0.020 \\
\hline \multicolumn{4}{|l|}{ For logistic regression } \\
\hline \multirow[t]{2}{*}{ chronic cough $^{* *}$} & exposure to cigarette smoke in university & $6.06(2.35-15.61)$ & $<0.001$ \\
\hline & occupational exposure to waterpipe smoke & $7.08(2.76-18.17)$ & $<0.001$ \\
\hline \multirow[t]{3}{*}{ chronic sputum production*** } & married status versus unmarried & $6.40(1.06-38.81)$ & 0.043 \\
\hline & living near a heavy traffic road & $9.49(0.98-92.18)$ & 0.052 \\
\hline & living near a local power generator & $7.54(1.27-44.79)$ & 0.026 \\
\hline \multirow[t]{3}{*}{ chronic allergy ${ }^{\mathrm{a}}$} & male gender versus female & $7.81(1.28-47.62)$ & 0.026 \\
\hline & living near a local power generator & $5.52(1.24-24.61)$ & 0.025 \\
\hline & family history of a chronic respiratory disease & $17.01(1.80-160.93)$ & 0.013 \\
\hline
\end{tabular}

$\beta$ - multiple regression coefficient; $\mathrm{CI}$ - confidence interval.

* Multiple linear regression; $\mathrm{R}=0.875$; adjusted $\mathrm{R}^{2}=0.76$; unretained variables include: age, marital status, biomass fuel use for home heating, house close to a heavy traffic road, house close to a local power generator, home exposure to tobacco smoke, and body mass index.

** Logistic regression forward stepwise likelihood ratio; Nagelkerke R Square = 0.194; P-value for Hosmer \& Lemeshow test = 1.000; unretained variables in the model include: age, sex, marital status, education, house close to a heavy traffic road, house close to a local power generator, biomass fuel use for house heating, family history of chronic respiratory disease, home exposure to tobacco smoke, chronic respiratory disease during childhood, parental smoking during childhood and fetal life, and body mass index.

*** Logistic regression forward stepwise likelihood ratio; Nagelkerke R Square = 0.298; P-value for Hosmer \& Lemeshow test $=0.630$; unretained variables in the model include: occupational waterpipe smoke exposure, university cigarette smoke exposure, age, sex, education, biomass fuel use for house heating, family history of chronic respiratory disease, home exposure to tobacco smoke, chronic respiratory disease during childhood, parental smoking during childhood and fetal life, and body mass index.

${ }^{a}$ Logistic regression forward stepwise likelihood ratio; Nagelkerke R Square $=0.300$; P-value for Hosmer \& Lemeshow test = 0.270; unretained variables in the model include: occupational waterpipe smoke exposure, university cigarette smoke exposure, age, marital status, education, living near a heavy traffic road, using biomass fuel for heating, exposure to tobacco smoke at home, chronic respiratory disease during childhood, parental smoking during childhood and fetal life and body mass index. 
( $\beta=6.03)$ exhaled higher levels of carbon monoxide. These levels are also augmented by the number of weekly hours of occupational exposure to waterpipe smoke by the workers in restaurants $(\beta=1.46)$ as well as the number of daily hours of exposure to cigarette smoke in the university ( $\beta=1.14$ ), showing a dose-effect relationship between duration of smoking and carbon monoxide levels. All other variables were removed from the model.

On the other hand, only exposure to cigarette smoke in university (adjusted odds ratio $(\mathrm{ORa})=6.06)$ and occupational exposure to waterpipe smoke $(\mathrm{ORa}=7.08)$ were predictors of manifesting a chronic cough, whereas being married $(\mathrm{ORa}=6.40)$, living near a heavy traffic $\operatorname{road}(\mathrm{ORa}=9.49$; borderline result $)$ or near a local power generator $(\mathrm{ORa}=7.54)$ were significantly associated with chronic sputum production.

Finally, correlates of chronic allergies were: being male $(\mathrm{ORa}=7.81)$, living near a local power generator $(\mathrm{ORa}=5.52)$ and having a family history of chronic respiratory diseases $(\mathrm{ORa}=17.01)$.

\section{DISCUSSION}

In this pilot study, we have found that the expiredair CO level was significantly higher in the breath of passive smokers exposed to waterpipe smoke, followed by those exposed to cigarette smoke and was lowest in the non-exposed. These results were confirmed by multivariate analysis and dose-effect relationship between duration of exposure and elevated level of carbon monoxide. Our results are similar to those of other authors: SHS is a significant source of exposure to CO for passive smokers $[23,24]$. We should note that the subjects exposed to waterpipe smoke had the lowest exposure rates at home, indicating that the majority were solely exposed to SHS in the workplace. Actually, Lam et al. [25] concluded that at work, environmental tobacco smoke [ETS] exposure had stronger effects because subjects spent more time among a larger number of smoking individuals at work than at home. Furthermore, the workplace, in our case, consists of restaurants serving waterpipe. In a review of the literature, Siegel et al. [26] reported that the levels of ETS in restaurants and bars were 1.6 to 2.0 times higher than in other types of workplace, and 1.5 times higher than those found in homes with at least one smoker, placing ETS as a particular concern to the hospitality employees.

Usually, an expired CO of 0 to 6 ppm represents a nonsmoker, 7 to 10 a light smoker, 11 to 20 a smoker, and more than 20 a heavy smoker. Thus, according to their ECO level, the non-exposed subjects in our sample would be classified as non-smokers, the exposed to cigarette smoke as smokers, and those exposed to waterpipe smokers as heavy smokers, although all declared to be non active smokers. Actually, the fact that non active smoking workers, exposed to SHS, have ECO levels that would classify them as active smokers was also seen in other studies [27,28].

In the multivariate analysis, exhaled levels of $\mathrm{CO}$ were also positively affected by the weekly hours of occupational exposure to waterpipe smoke by the hospitality workers, and by daily hours of exposure to cigarette smoke in universities as well, but to a lesser extent. This shows a clear doseresponse relationship between exposure duration and $\mathrm{CO}$ level. Moreover, the greater increase due to waterpipe exposure versus cigarette is visible here: this difference might be accounted for by the difference in hours of exposure, since the restaurant workers spend $61.08 \mathrm{~h} /$ week exposed to waterpipe smoke, while exposure of university students was significantly lower when calculated per week. Another explanation of the difference in levels of ECO might be previous findings showing that waterpipe use is associated with greater CO exposure than cigarette use [29]. Other studies also had results similar to ours, showing that a waterpipe smoker was found to likely emit as much $\mathrm{CO}$ as 7,8 or even 10 cigarette smokers [19,30,31].

On another hand, although $\mathrm{CO}$ has been shown to vary with age [32-35] and exposure to combustion of petroleum 
derogates by cars and coal ovens [36], there were no significant differences concerning these matters between the groups. In fact, age and other sources of $\mathrm{CO}$ were removed in the multivariate analysis; this adjusts the age differences in our sample as well as the different exposures to generator exhausts. Some socio-demographic characteristics were kept in the model: male gender and lower education. This was similar to what was found in another study, where non-smoking male subjects had higher ECO levels compared with female subjects [35].

Carbon monoxide measurement use deserves our attention; it could be considered a strong point since self-reported passive smoke exposure was not the only proxy for true exposure levels, as objective measurements of ECO were also performed. Although urine cotinine and carboxyhemoglobin levels were not evaluated in this study, we chose $\mathrm{CO}$ as a biological marker of SHS because it is quick and easy to measure, cheaper than performing a series of laboratory assays, non-invasive, thus more acceptable to the participant [36,37]. Despite the non-specificity of CO to tobacco smoke, the latter remains the most important source of $\mathrm{CO}$ in indoor places, and it can be used as a biomarker for passive tobacco exposure [38-40]. In fact, using carbon monoxide to evaluate passive smoking has been useful in case of cigarettes: carbon monoxide could be considered one of the most toxic substances present in the gas-phase of second-hand tobacco smoke [41]. Carbon monoxide could also be considered as an easy and rapid biomarker, i.e. primarily of interest for the assessment of the exposure and early biological effects in epidemiology as well as occupational and environmental medicine [42]: microenvironmental measurements of $\mathrm{CO}$ were shown to well represent the personal exposures of individuals within that microenvironment; $\mathrm{CO}$ can be measured accurately by instrumental means and it therefore represents an ideal tracer of exposure $[43,44]$. Finally, we had previously shown that carbon monoxide could be used as a biomarker of exposure to many factors in the Lebanese population, which include active smoking, passive smoking, and environmental exposure to respiratory toxins [21].

As for the respiratory symptoms, individuals exposed to waterpipe smoke and those exposed to cigarette smoke both manifested more chronic cough than non-exposed individuals who had, however, a higher rate of chronic allergy. In the multivariate analysis, chronic cough was predicted by exposure predictors. Occupational exposure to waterpipe smoke was the most predictive of it, followed by exposure to cigarette smoke in universities. Chronic cough has already been associated with passive smoking [45], and all workers exposed to smoke during their work had higher prevalence of respiratory and irritative symptoms [46]. Additionally, research studying the effects of smoking ban found that the decrease in prevalence of cough and phlegm was significant and relevant in all workers, whether they were smokers or non-smokers $[47,48]$. Chronic cough was also associated with higher levels of $\mathrm{CO}$ that may reflect the inflammation of airways [42], since a study showed that smokers who complained of frequent cough and sputum production had higher levels of ECO compared with smokers without such complaints [43]. Chronic cough and morning cough of the restaurant workers also seemed to be affected by the years working in the concerned restaurant, showing again a dose-response relationship.

On the other hand, chronic sputum and chronic allergies were mainly predicted by socio-demographic characteristics, and were both affected by living near a local power generator. In fact, epidemiological, human, and animal studies all suggest that diesel exhaust particulates, linked to traffic-related and industrial activities are involved in the pathogenesis of asthma, sputum production, allergic rhinitis, and other allergic disorders [49,50]. This may explain the higher chronic allergies rate found in non-exposed participants since they lived closest to a local power generator. Moreover, family history of chronic respiratory diseases was the main predictor of chronic allergies, as it is well known that allergies have a genetic component [51-53]. 
Our study may have several limitations. In our sample, the participants exposed to waterpipe smoke were only men, significantly older than other subjects. They mainly had lower education than the rest and half of them were married, whereas the other groups were all single university students. Moreover, those exposed to cigarette smoke had the highest exposure rate to maternal smoke during childhood. These differences were however adjusted for in the multivariate analysis. Also working in a restaurant that serves waterpipe does not preclude exposure to cigarette smoke; however, we expect the latter to be of minor importance since there are very low proportions of cigarette smokers in these specific restaurants (general observation).

Moreover, the design may not include people with serious respiratory symptoms who had left their job, thus the impact could be underestimated due to a possible healthy worker effect. A validation of outcome measures for respiratory symptoms was not conducted, but these measures have been tested in many other studies which found them to have a high validity [54].

Furthermore, temporal associations cannot be inferred for some variables, because of the cross-sectional nature of the design; however, we could show relationships between the duration of exposure and the health effects, supporting a causal association hypothesis. Given the small sample size of our pilot study, some results may not be significant in multivariate analyses; larger scale studies that take into account these limitations and give more stable results will be necessary to confirm our findings. This will also be useful to further apply the anti-smoking law and fix the limits of passive smoking exposure in the workplace.

\section{CONCLUSION}

In conclusion, passive smoking at restaurants serving waterpipes or at university cafeterias allowing cigarette smoking indoor was associated with an increased prevalence of chronic cough and higher ECO levels, with obvious poorer results with waterpipe exposure. In Lebanon, those who work in waterpipe serving restaurants continue to be exposed to the harmful effects of tobacco smoke. Our results can be used as ammunition in the struggle against smoking in public places, with a focus on waterpipe.

\section{REFERENCES}

1. Öberg M, Jaakkola MS, Prüss Üstün A, Peruga A, Woodward A. Global estimate of the burden of disease from second-hand smoke. Geneva: World Health Organization; 2010 [cited 2013 Feb 20]. Available from: http://www.who.int/iris/ handle/10665/44426.

2. Flouris AD, Faught BE, Klentrou P. Cardiovascular disease risk in adolescent smokers: Evidence of a "smoker lifestyle". J Child Health Care. 2008;12(3):221-31, http://dx.doi.org/ 10.1177/1367493508092509.

3. Mackay J, Eriksen M. The tobacco atlas. Geneva: World Health Organization; 2008.

4. U.S. Department of Health and Human Services. The Health Consequences of Involuntary Exposure to Tobacco Smoke: A Report of the Surgeon General. Atlanta, GA: U.S. Department of Health and Human Services, Centers of Disease Control and Prevention, Coordinating Center for Health Promotion, National Center for Chronic Disease Prevention and Health Promotion, Office on Smoking and Health; 2006. p. 12-136.

5. Öberg M, Jaakkola MS, Woodward A, Peruga A, PrüssÜstün A. Worldwide burden of disease from exposure to second-hand smoke: A retrospective analysis of data from 192 countries. Lancet. 2011;377(9760):139-46, http://dx.doi. org/10.1016/S0140-6736(10)61388-8.

6. Kawachi I, Colditz GA. Workplace exposure to passive smoking and risk of cardiovascular disease: Summary of epidemiologic studies. Environ Health Perspect. 1999;107 (6 Suppl):847-51, http://dx.doi.org/10.2307/3434564.

7. Bos RP, Henderson PT. Genotoxic risk of passive smoking. Rev Environ Health. 1984;4(2):161-78. 
8. Greer JR, Abbey DE, Burchette RJ. Asthma related to occupational and ambient air pollutants in nonsmokers. J Occup Med. 1993;35(9):909-15, http://dx.doi. org/10.1097/00043764-199309000-00014.

9. Thorn J, Brisman J, Torén K. Adult-onset asthma is associated with self-reported mold or environmental tobacco smoke exposures in the home. Allergy. 2001;56(4):287-92, http://dx.doi.org/10.1034/j.1398-9995.2001.00805.x.

10. Radon K, Nowak D. [Passive smoking - Current position of science]. Dtsch Med Wochenschr. 2004;129(4):157-62, http://dx.doi.org/10.1055/s-2004-817603. German.

11. Masjedi MR, Kazemi H, Johnson DC. Effects of passive smoking on the pulmonary function of adults. Thorax. 1990;45(1):27-31, http://dx.doi.org/10.1136/thx.45.1.27.

12. Carey IM, Cook DG, Strachan DP. The effects of environmental tobacco smoke exposure on lung function in a longitudinal study of British adults. Epidemiology. 1999;10(3): 319-26, http://dx.doi.org/10.1097/00001648-199905000-00022.

13. Salameh P, Waked M, Khayat G, Khoury F, Salame J, Dramaix M. Waterpipe smoking and dependence are associated with chronic bronchitis: A case control study. Eastern Mediterr Health J. 2012;18(10):996-1004.

14. Salameh P, Khayat G, Waked M, Dramaix M. Waterpipe smoking and dependence are associated with Chronic Obstructive Pulmonary Disease: A case-control study. Open Epidemiol J. 2012;5:36-44, http://dx.doi.org/10.2174/18742 97101205010036.

15. Akl EA, Gaddam S, Gunukula SK, Honeine R, Jaoude PA, Irani J. The effects of waterpipe tobacco smoking on health outcomes: A systematic review. Int J Epidem. 2010;39: 857-9, http://dx.doi.org/10.1093/ije/dyq002.

16. Fromme H, Dietrich S, Heitmann D, Dressel H, Diemer J, Schulz T, et al. Indoor air contamination during a waterpipe (narghile) smoking session. Food Chem Toxicol. 2009;47(7):1636-41, http://dx.doi.org/10.1016/j.fct. 2009.04.017.

17. Shihadeh AL, Eissenberg TE. Significance of smoking machine toxicant yields to blood-level exposure in water pipe tobacco smokers. Cancer Epidemiol Biomarkers Prev. 2011;20(11):2457-60, http://dx.doi.org/10.1158/10559965.EPI-11-0586.

18. Aoun Z, Salameh P, Waked M. Saliva cotinine and exhaled carbon monoxide in real life waterpipe smokers. Inhal Toxicol. 2007;19(9):771-7, http://dx.doi.org/10.1158/10559965.EPI-11-0586.

19. Salameh P, Aoun Z, Waked M. Saliva cotinine and exhaled carbon monoxide in real life narghile (waterpipe) smokers: A post hoc analysis. Tobacco Use Insights. 2009;2:1-10.

20. Global strategy for the diagnosis, management and prevention of chronic obstructive pulmonary disease. Global Initiative for Chronic Obstructive Lung Disease; 2006 [cited 2014 Feb 7]. Available from: http:// www.goldcopd.org.

21. Salameh P, Khayat G, Waked M. Validation of the Respiratory Toxics Exposure Score (RTES) for chronic obstructive pulmonary disease screening. Int J Occup Med Environ Health. 2011;24(4):339-47, http://dx.doi.org/10.2478/s13382011-0043-x.

22. Boos DD, Hughes-Oliver JM. How large does $n$ have to be for $Z$ and t intervals? Am Statistician. 2000;54(2):121-8, http://dx.doi.org/10.2307/2686030.

23. Czogala J, Goniewicz ML. The complex analytical method for assessment of passive smokers' exposure to carbon monoxide. J Anal Toxicol. 2005;29(8):830-4, http://dx.doi. org/10.1093/jat/29.8.830.

24. Bernstein JA, Alexis N, Bacchus H, Bernstein IL, Fritz P, Horner $\mathrm{E}$, et al. The health effects of non-industrial indoor air pollution. J Allergy Clin Immunol. 2008;121(3):585-91, http://dx.doi.org/10.1016/j.jaci.2007.10.045.

25. Lam TH, Ho LM, Hedley AJ, Adab P, Fielding R, McGhee SM, et al. Environmental tobacco smoke exposure among police officers in Hong Kong. JAMA. 2000; 284(6):756-63, http://dx.doi.org/10.1001/jama.284.6.756.

26. Siegel M. Involuntary smoking in the restaurant workplace. A review of employee exposure and health effects. JAMA. 1993;270(4):490-3, http://dx.doi.org/10.1001/jama. 1993.03510040094036. 
27. McCaffrey M, Goodman P, Gavigan A, Kenny C, Hogg C, Byrne L, et al. Should any workplace be exempt from smokefree law: The Irish experience. J Environ Public Health. 2012;2012:545483, http://dx.doi.org/10.1155/2012/545483.

28. Goodman P, Agnew M, McCaffrey M, Paul G, Clancy L. Effects of the Irish smoking ban on respiratory health of bar workers and air quality in Dublin pubs. Am J Respir Crit Care Med. 2007;175(8):840-5, http://dx.doi.org/10. 1164/rccm.200608-1085OC.

29. Eissenberg T, Shihadeh A. Waterpipe tobacco and cigarette smoking: Direct comparison of toxicant exposure. Am J Prev Med. 2009;37(6):518-23, http://dx.doi.org/10.1016/ j.amepre.2009.07.014.

30. Zahran FM, Ardawi MS, Al-Fayez SF. Carboxyhemoglobin concentrations in smokers of sheesha and cigarettes in Saudi Arabia. Br Med J (Clin Res Ed). 1985;291(6511): 1768-70, http://dx.doi.org/10.1136/bmj.291.6511.1768-a.

31. Singh S, Soumya M, Saini A, Mittal V, Singh UV, Singh V. Breath carbon monoxide levels in different forms of smoking. Indian J Chest Dis Allied Sci. 2011;53(1):25-8.

32. Daher N, Saleh R, Jaroudi E, Sheheitli H, Badr T, Sepetdjian $\mathrm{E}$, et al. Comparison of carcinogen, carbon monoxide, and ultrafine particle emissions from narghile waterpipe and cigarette smoking: Sidestream smoke measurements and assessment of second-hand smoke emission factors. Atmos Environ. 2010;44(1):8-14, http://dx.doi.org/10.1016/ j.atmosenv.2009.10.004.

33. Carmeli E, Coleman R, Reznick AZ. The biochemistry of aging muscle. Exp Gerontol. 2002;37(4):477-89, http:// dx.doi.org/10.1016/S0531-5565(01)00220-0.

34. Gil L, Siems W, Mazurek B, Gross J, Schroeder P, Voss $\mathrm{P}$, et al. Age-associated analysis of oxidative stress parameters in human plasma and erythrocytes. Free Radic Res. 2006;40(5):495-505, http://dx.doi.org/10.1080/ 10715760600592962.

35. Carpagnano GE, Kharitonov SA, Foschino-Barbaro MP, Resta O, Gramiccioni E, Barnes PJ. Increased inflammatory markers in the exhaled breath condensate of cigarette smokers. Eur Respir J. 2003;21(4):589-93, http://dx.doi.org/ 10.1183/09031936.03.00022203.

36. Middleton ET, Morice AH. Breath carbon monoxide as an indication of smoking habit. Chest. 2000;117(3):758-63, http://dx.doi.org/10.1378/chest.117.3.758.

37. Laranjeira R, Pillon S, Dunn J. Environmental tobacco smoke exposure among non-smoking waiters: Measurement of expired carbon monoxide levels. Sao Paulo Med J. 2000;118(4):89-92, http://dx.doi.org/10.1590/S151631802000000400003.

38. Issa JS, Abe TMO, Pereira AC, Megid MC, Shimabukuro CE, Valentin LSO, et al. The effect of São Paulo's smoke-free legislation on carbon monoxide concentration in hospitality venues and their workers. Tob Control. 2011;20(2):156-62, http://dx.doi.org/10.1136/tc.2010.037614.

39. US Department of Health and Human Services [Internet]. The health benefits of smoking cessation: A report of the surgeon general, 1990. Washington (DC): Department of Health and Human Services; 1990 [cited 2014 Feb 7]. Available from: http:/profiles.nlm.nih.gov/NN/B/B/C/T/_nnbbct.pdf.

40. Taniguchi S, Niitsuya M, Inoue Y, Katagiri H, Kadowaki T, Aizawa Y. Evaluation of passive smoking by measuring urinary trans, trans-muconic acid and exhaled carbon monoxide levels. Ind Health. 1999;37(1):88-94, http://dx.doi. org/10.2486/indhealth.37.88.

41. Goniewicz ML, Czogała J, Kośmider L, Koszowski B, Zielińska-Danch W, Sobczak A. Exposure to carbon monoxide from second-hand tobacco smoke in Polish pubs. Centr Eur J Public Health. 2009;17(4):220-2.

42. Scherer G. Carboxyhemoglobin and thiocyanate as biomarkers of exposure to carbon monoxide and hydrogen cyanide in tobacco smoke. Exp Toxicol Pathol. 2006;58(2-3): 101-24, http://dx.doi.org/10.1016/j.etp.2006.07.001.

43. Harrison RM, Thornton CA, Lawrence RG, Mark D, Kinnersley RP, Ayres JG. Personal exposure monitoring of particulate matter, nitrogen dioxide, and carbon monoxide, including susceptible groups. Occup Environ Med. 2002;59:671-9, http://dx.doi.org/10.1136/oem.59.10.671. 
44. Jones AYM, Lam PKW. End-expiratory carbon monoxide levels in healthy subjects living in a densely populated urban environment. Sci Total Environ. 2006;354(2-3):150-6, http:// dx.doi.org/10.1016/j.scitotenv.2005.02.018.

45. Hammad M, Atta K, Manzoor M, Tariq M, Saeed Z, Masood Z, et al. Association of passive smoking with respiratory symptoms and clinical correlates, among married women, in a rural community in Islamabad. J Pak Med Assoc. 2010;60(7):601-4.

46. Hersoug L-G, Husemoen LLN, Sigsgaard T, Madsen F, Linneberg A. Indoor exposure to environmental cigarette smoke, but not other inhaled particulates associates with respiratory symptoms and diminished lung function in adults. Respirology. 2010;15(6):993-1000, http://dx.doi.org/10.1111/ j.1440-1843.2010.01758.x.

47. Lesage F-X, Deschamps F, Jurca D. Illegal passive smoking at work. Adv Prev Med. 2011;2011:975678, http://dx.doi. org/10.4061/2011/975678.

48. Eagan TML, Hetland J, Aarř LE. Decline in respiratory symptoms in service workers five months after a public smoking ban. Tob Control. 2006;15(3):242-6, http://dx.doi. org/10.1136/tc.2005.015479.
49. Takizawa H. Impact of air pollution on allergic diseases. Korean J Intern Med. 2011;26(3):262-73, http://dx.doi. org/10.3904/kjim.2011.26.3.262.

50. Miyamoto T. Epidemiology of pollution-induced airway disease in Japan. Allergy. 1997;52(38 Suppl):30-4, http://dx.doi. org/10.1111/j.1398-9995.1997.tb04867.x.

51. Lorente F, Isidoro M, Dávila I, Laffond E, Moreno E. Prevention of allergic diseases. Allergol Immunopathol (Madr). 2007;35(4):151-6, http://dx.doi.org/10.1157/13108226.

52. Omenaas E, Svanes C, Janson C, Toren K, Jogi R, Gislason $\mathrm{T}$, et al. What can we learn about asthma and allergy from the follow-up of the RHINE and the ECRHS studies? Clin Respir J. 2008;2(Suppl 1):45-52, http://dx.doi. org/10.1111/j.1752-699X.2008.00083.x.

53. Pin I, Pilenko-McGuigan C, Cans C, Gousset M, Pison C. Epidemiology of respiratory allergy in children. Arch Pediatr. 1999;6(Suppl 1):6S-13S, http://dx.doi.org/10.1016/ S0929-693X(99)80240-1.

54. Kelly FJ, Fussell JC. Air pollution and airway disease. Clin Exp Allergy. 2011;41(8):1059-71, http://dx.doi.org/10.1111/ j.1365-2222.2011.03776.x.

This work is available in Open Access model and licensed under a Creative Commons Attribution-NonCommercial 3.0 Poland License - http://creativecommons.org/ licenses/by-nc/3.0/pl/deed.en. 